\title{
Ocorrência de algas cianofíticas em água de dessedentação de bovinos criados extensivamente ${ }^{1}$
}

\author{
Ariane C. Silva ${ }^{2}$, Aires M. Souza ${ }^{3}$ e Iveraldo S. Dutra ${ }^{4 *}$
}

\begin{abstract}
Silva A.C., Souza A.M. \& Dutra I.S. 2014. [Occurrence of blue-green algae in the drinking water of extensively raised cattle.] Ocorrência de algas cianofíticas em água de dessedentação de bovinos criados extensivamente. Pesquisa Veterinária Brasileira 34(5):415420. Departamento de Apoio, Produção e Saúde Animal, Faculdade de Medicina Veterinária de Araçatuba, Universidade Estadual Paulista, Rua Clóvis Pestana 793, Cx. Postal 533, Jardim Dona Amélia, Araçatuba, SP 16050-680, Brazil. E-mail: isdutra@fmva.unesp.br

In extensive animal husbandry, natural or artificial ponds allow direct access of cattle to water but result in degradation of water quality and in increased health risks. Under such circumstances eutrophication occurs and consequently algal bloom, among them toxigenic cyanobacteria. The present study aimed to report the occurrence of cyanobacteria in the drinking water of cattle and to describe their physical and chemical parameters, as $\mathrm{pH}$, temperature and dissolved oxygen. Nineteen samples of natural ponds or water troughs formed predominantly as result of rainfall from six farms located in the Southeast and Midwest regions of Brazil were analyzed for the presence of cyanobacteria, and $\mathrm{pH}$, temperature and dissolved oxygen was measured. Microcystis and/or Merismopedia were detected in two ponds; one of them was covered with intense flowering. The values of $\mathrm{pH}$, temperature and dissolved oxygen in 19 collections were $\mathrm{pH} 7.2-9.7,31-34^{\circ} \mathrm{C}$ and $7.8-30 \mathrm{mg} / \mathrm{l}$ respectively. Also non-pathogenic algae of several genera were detected besides the occurrence or not of cianogenics. Under these conditions, the common practices of drinking water supply for extensively raised cattle and the possibilities of eutrophication and cyanobacterial growth bring potential risks for animal health.
\end{abstract}

INDEX TERMS: Water, livestock, eutrophication, cyanobacteria, blue-green algae.

RESUMO.- Na pecuária extensiva, os bebedouros naturais ou artificiais possibilitam o acesso direto dos bovinos ao seu interior e trazem como consequência a degradação da qualidade da água e o aumento dos riscos sanitários. Em tais circunstâncias ocorre a eutrofização e consequentemente a floração de algas, dentre elas cianobactérias toxigênicas. 0 presente estudo teve por objetivo verificar a ocorrência de

\footnotetext{
${ }^{1}$ Recebido em 20 de novembro de 2013.

Aceito para publicação em 6 de maio de 2014.

${ }^{2}$ Programa de Pós-graduação em Ciência Animal, Faculdade de Medicina Veterinária de Araçatuba, Universidade Estadual Paulista (Unesp), Rua Clovis Pestana 793, Jardim Dona Amélia, Araçatuba, SP 16050-680, Brasil. E-mail: anecsilva@hotmail.com

${ }^{3}$ Departamento de Medicina Veterinária Preventiva, Escola de Veterinária e Zootecnia, Universidade Federal de Goiás (UFG), Campus Samambaia, Cx. Postal 131. Goiânia, G0 74001-970, Brasil. E-mail: airesvet@gmail.com

${ }^{4}$ Departamento de Apoio, Produção e Saúde Animal, Faculdade de Medicina Veterinária de Araçatuba, Universidade Estadual Paulista (Unesp), Rua Clóvis Pestana 793, Cx. Postal 533, Jardim Dona Amélia, Araçatuba, SP 16050-680, Brasil. *Autor para correspondência: isdutra@fmva.unesp.br
}

cianobactérias de interesse sanitário em água de dessedentação de bovinos e descrever os seus parâmetros físico-químicos $\mathrm{pH}$, temperatura e oxigênio dissolvido. Foram examinadas 19 amostras de água de cacimbas ou bebedouros naturais formados predominantemente em decorrência da precipitação pluviométrica, coletadas em seis propriedades rurais localizadas nas regiões Sudeste e Centro-Oeste, para a presença de cianobactérias e mensurados os valores de $\mathrm{pH}$, temperatura e oxigênio dissolvido. Microcystis e/ou Merismopedia foram detectadas em dois bebedouros; em um dos quais havia intensa floração. Os valores de $\mathrm{pH}$, temperatura e oxigênio dissolvido nas 19 coleções oscilaram entre $\mathrm{pH} 7,2-9,7,31-34^{\circ} \mathrm{C}$ e $7,8-30 \mathrm{mg} / \mathrm{l}$, respectivamente. Foram detectadas ainda algas consideradas não patogênicas de diversos gêneros, em conjunto ou não com a ocorrência das cianofíticas. Nessas condições, as práticas comuns de oferta de água de dessedentação na bovinocultura extensiva, as possibilidades de eutrofização e a contaminação por cianobactérias trazem potenciais riscos à saúde dos animais. 
TERMOS DE INDEXAÇÃO: Água, bovinocultura, eutrofização, cianobactéria, algas cianofíticas.

\section{INTRODUÇÃO}

O fornecimento tradicional de água aos bovinos criados em sistema de produção extensivo representa um desafio para a produção animal. Os bebedouros naturais ou artificiais, construídos diretamente no solo, possibilitam o acesso dos animais ao seu interior, o que favorece a contaminação das coleções de água estagnada com fezes e urina e traz consequências para a saúde animal (Souza et al. 2006).

A contaminação constante pelos dejetos dos animais, ou ainda pelas práticas agrícolas, quando ocorre em ecossistemas aquáticos leva à eutrofização, um enriquecimento artificial causado pelo aumento das concentrações de nutrientes na água, principalmente por compostos nitrogenados e fosfatados (Veiga 2008). Em condições naturais a eutrofização se associa a elevadas temperaturas e longos períodos de estiagem, que ocasionam uma maior evaporação da água e consequentemente uma elevação na concentração desses nutrientes (Jardim et al. 2007).

A eutrofização gera um intenso crescimento biológico, com o desenvolvimento de uma comunidade fitoplanctônica, geralmente com predominância das cianobactérias em relação às demais espécies de algas (Assis 2006). Dotadas de grande plasticidade fenotípica e ecológica, com possibilidades de adaptação aos mais variados ambientes, as cianobactérias são encontradas em praticamente todas as partes do mundo (Magalhães et al. 2006).

Dentre as principais causas da dominância das cianobactérias no meio aquático, destacam-se a baixa razão entre nitrogênio e fósforo totais, baixa concentração de $\mathrm{CO}_{2}$ ou alto $\mathrm{pH}$, pequena pressão de herbivoria, alta temperatura, possibilidade de regular sua flutuação em ambientes com alta e baixa turbulência, baixa intensidade luminosa, capacidade de armazenar fósforo, produção e secreção de substâncias alelopáticas (Domingos 2001).

As vias de exposição mais comuns do homem e animais para as cianotoxinas produzidas pelos micro-organismos são a ingestão acidental de água, através dos poros da pele e mucosa, hemodiálise, inalação e consumo de alimentos contaminados (Fonseca 2007). Algumas florações de cianobactérias provocam alterações no gosto e no sabor da água, redução no oxigênio dissolvido, além da liberação de toxinas prejudiciais à saúde humana e animal. Existem registros de morte por envenenamento de bovinos, cavalos, porcos, ovelhas, cães, peixes e invertebrados pela ingestão ou contato com as florações tóxicas (Carmichael 1994, Falconer 1999), causadas pelos gêneros Microcystis, Anaebaena, Aphanizomenon, Nodularia, Nostoc e Oscillatoria. Na África do Sul, embora estes gêneros todos ocorram, a intoxicação nos animais de produção está associada principalmente à água contaminada por Microcystis aeruginosa e possivelmente por Nodularia spumigena (Kellerman et al. 2005).

As toxinas produzidas por cianobactérias são enquadradas em três categorias, segundo seus efeitos tóxicos em mamíferos: neurotoxinas, dermatotoxinas (lipopolissacarídeos), e hepatotoxinas (Falconer 1993).

Dentre as neurotoxinas, são conhecidos três diferen- tes tipos: anatoxina-a, um alcaloide neurotóxico que age como potente bloqueador neuromuscular pós-sináptico de receptores nicotínicos e colinérgicos (Funasa 2003); anatoxina(s), um organofosforado natural que tem o mecanismo de ação semelhante à anatoxina-a, inibindo a ação da acetilcolinesterase e impedindo a degradação da acetilcolina ligada aos receptores, e que provoca intensa salivação observada em animais intoxicados (Carmichael 1992, Falconer 1998); saxitoxinas, que inibem a condução nervosa por bloqueio dos canais de sódio, afetando ou a permeabilidade ao potássio ou a resistência das membranas (Carmichael 1994).

As dermatotoxinas são toxinas formadas por compostos químicos bioativos que causam irritação ao contato, e apesar de não matarem os organismos, podem lesar as suas células. Elas têm a função de aumentar as defesas das cianobactérias contra as espécies do zooplâncton (Domingos 2001).

Já as hepatotoxinas apresentam uma ação mais lenta, causando o tipo mais comum de intoxicação e provocando hepatoenterites. Atualmente os valores aceitáveis para alimentos contaminados com microcistinas são, segundo a Organização Mundial da Saúde (OMS), expressados através

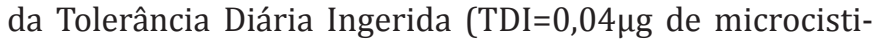
nas $/ \mathrm{kg} /$ dia). A concentração máxima de ingestão da toxina na água de consumo permitida é $1 \mu \mathrm{g} /$ litro/dia (Falconer et al. 1994). 0 fígado é o órgão alvo da microcistina (McDermott et al. 1998, Zhan et al. 2004).

Na produção animal os estudos que relacionam a ocorrência de intoxicação por cianobactérias são relativamente escassos. Na revisão de literatura brasileira compulsada não foi possível encontrar menção à ocorrência de intoxicações em bovinos, da mesma forma que a pesquisa de cianobactérias potencialmente tóxicas em água de dessedentação de bovinos. Embora não se tenha o relato da associação de problemas sanitários em bovinos no país à ocorrência de cianobactérias, a presença dos micro-organismos, das suas florações e das condições epidemiológicas favoráveis nos sistemas de produção de bovinos indicam a necessidade de se ampliar o conhecimento sobre a questão. Dessa forma, o objetivo do presente estudo foi o de verificar a ocorrência de cianobactérias potencialmente patogênicas em água de dessedentação de bovinos e descrever alguns parâmetros físico-químicos ( $\mathrm{pH}$, temperatura e oxigênio dissolvido) da água nos locais de coleta das amostras.

\section{MATERIAL E MÉTODOS}

Coleta das amostras. As amostras de água de bebedouros foram coletadas em propriedades rurais localizadas nos municípios de Brasilândia (MS, n=4), Guararapes ( $\mathrm{SP}, \mathrm{n}=5$ ), Lavínia (SP, $\mathrm{n}=1)$, Nova Crixás $(\mathrm{n}=3)$, Aruanã $(\mathrm{n}=3)$ e São Miguel do Araguaia (GO, n=3), com criação de bovinos de corte ou leite e em ocasiões distintas, com exceção das amostras de Brasilândia e Lavínia, que foram coletas no período da seca (agosto e setembro, respectivamente). 0 critério foi por conveniência ou pelo histórico da ocorrência de florações de cianobactérias em anos anteriores (Brasilândia e Lavínia), associados ou não à suspeita não comprovada de ocorrência de problemas sanitários nos bovinos. Para a análise qualitativa das amostras, as coletas foram manuais, com o emprego de garrafas âmbar com capacidade mínima de 500ml, 
coletando-se as amostras sempre que possível $20 \mathrm{~cm}$ abaixo da superfície da água. Para análise da quantidade de oxigênio dissolvido (OD) foram realizadas coletas com frascos para demanda biológica de oxigênio, segundo Sant'anna \& Azevedo (2006). Para a conservação das amostras foi empregado lugol; para cada $100 \mathrm{ml}$ da amostra de água foi adicionado 0,3 a 1,0ml de lugol. As amostras coletadas e adicionadas de lugol foram mantidas sob refrigeração em caixa de isopor com gelo ou mantidos sob 2 a $8^{\circ} \mathrm{C}$ até o seu processamento para o cálculo da demanda biológica de oxigênio (DBO).

Identificação das cianobactérias. A classificação taxonômica das cianobactérias foi realizada através de exame microscópico, utilizando a objetiva de 40x para alguns tipos de algas e cianobactérias; para visualização de algumas cianobactérias utilizou-se a objetiva de 100x; foram realizadas 10 repetições para cada amostra, de acordo com critérios estabelecidos por Sant'anna \& Azevedo (2006).

Temperatura, pH e oxigênio dissolvido. Para cálculo do pH e da temperatura utilizou-se pH-metro eletrônico. Para análise do OD as amostras de água foram colocadas em frascos de DBO. Em seguida, foram adicionados $2 \mathrm{ml}$ de sulfato de manganês, mergulhando-se a ponta da pipeta no interior do líquido. Logo após, o frasco foi agitado para a homogeneização da mistura, seguindo-se a adição de $2 \mathrm{ml}$ de solução alcalina de iodeto-azida. Novamente a mistura foi agitada por inversões sucessivas. Em seguida, a mistura foi decantada por precipitação por 3 minutos; seguiu-se a adição de $2 \mathrm{ml}$ de ácido sulfúrico concentrado, agitando-se novamente como descrito anteriormente. Após essas etapas, mediu-se no cilindro graduado $200 \mathrm{ml}$ do líquido, que foi colocado em um Erlenmeyer de $500 \mathrm{ml}$, titulando-se com o reagente tiossulfato de sódio $0,025 \mathrm{~N}$ até o aparecimento de uma cor amarelo palha. Após esta operação foi adicionado 5 gotas de amido na qual houve o aparecimento de uma cor azul. Continuou-se a titulação até a viragem para incolor. $\mathrm{O}$ valor total do OD foi calculado conforme $\mathrm{o}$ gasto do tiossulfato usado no procedimento, conforme a American Public Health Association (1998).

\section{RESULTADOS E DISCUSSÃO}

A qualidade da água fornecida aos bovinos tem impacto sanitário e econômico na produção animal. São diversas as doenças de origem e veiculação hídrica de importância na saúde pública, mas relativamente pouco consideradas na bovinocultura. Na pecuária extensiva é comum a oferta de água superficial de rios, córregos, represas e cacimbas; estas construídas ou formadas naturalmente nas pastagens e que acumulam principalmente água de chuva. A eutrofização decorrente da contaminação das coleções de água pelas fezes e urina dos animais, e mesmo de práticas agrícolas, é a consequência natural e ocorre frequentemente em cacimbas (Souza et al. 2006). Nessas circunstâncias, os riscos para a saúde animal são reais e potencialmente crescentes. Embora os perigos das cianotoxinas sejam amplamente caracterizados para a saúde humana e algumas espécies animais (Carmichael 1994, Falconer 1999), praticamente nenhum enfoque no nosso meio considera os seus riscos para a saúde bovina.

Das 19 amostras de água de bebedouros de bovinos examinadas para a presença de algas cianofíticas, em duas foi possível identificar os gêneros Merismopedia (Fig.1A) e/ ou Microcystis (Fig.1B). Coletadas em seis propriedades rurais nos Estados de São Paulo, Mato Grosso do Sul e Goiás, as amostras de água superficial de cacimbas, predominan-
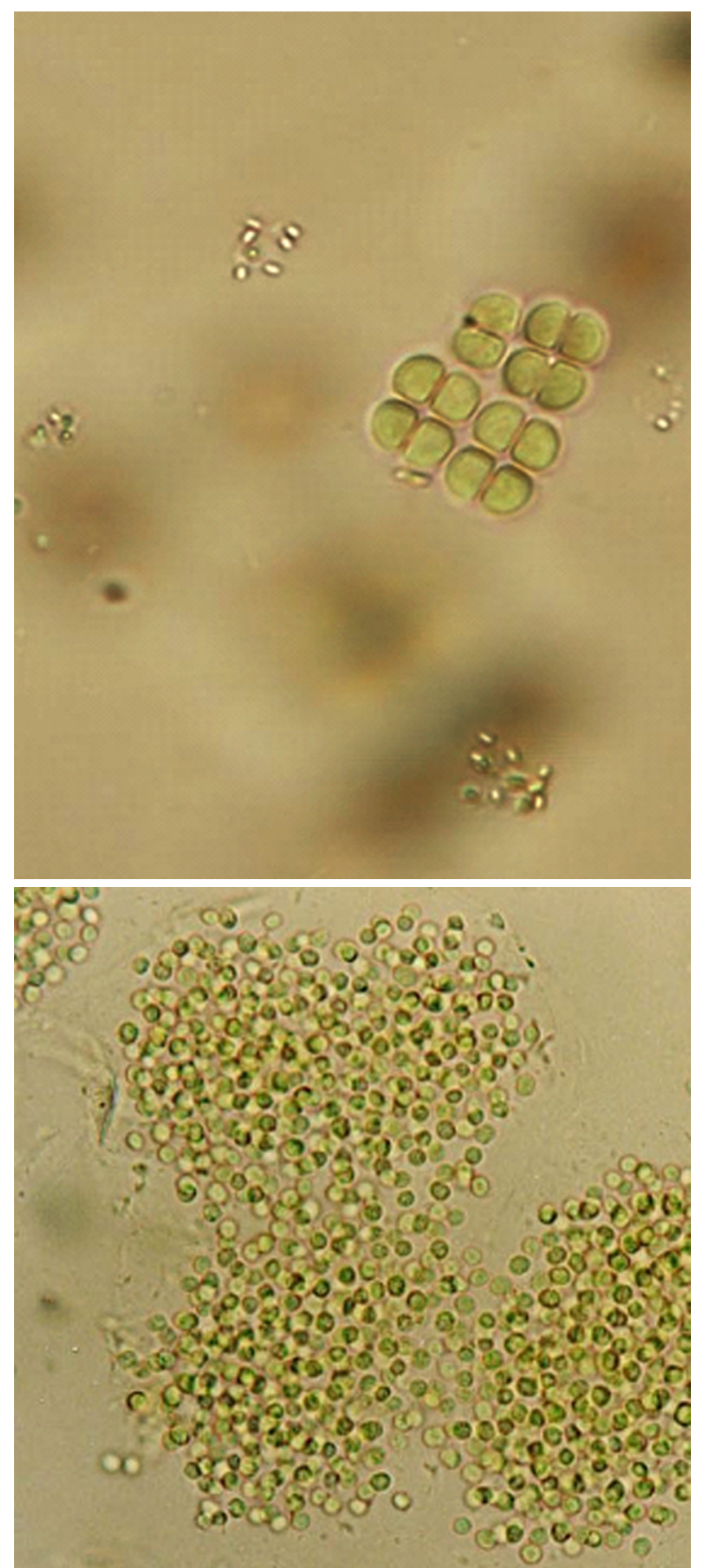

Fig.1. Aspectos morfológicos característicos dos gêneros. (A) $\mathrm{Me}$ rismopedia e (B) Microcystis, encontrados nas cacimbas e bebedouros com água de dessedentação de bovinos. Município de Brasilândia, Mato Grosso do Sul.

temente de precipitação pluviométrica, foram de coleções construídas para conter a erosão (propriedades rurais do estado de São Paulo) ou para serem empregadas como bebedouros de bovinos (Mato Grosso do Sul e Goiás).

Microcystis e Merismopedia foram detectadas em uma cacimba empregada como bebedouro principal (Fig.2) em divisória de dois pastos de 80 ha cada de propriedade rural do município de Brasilândia (MS), no qual por dois anos consecutivos ocorreram episódios com alta morbidade e baixa mortalidade de bovinos relacionadas à problema sa- 


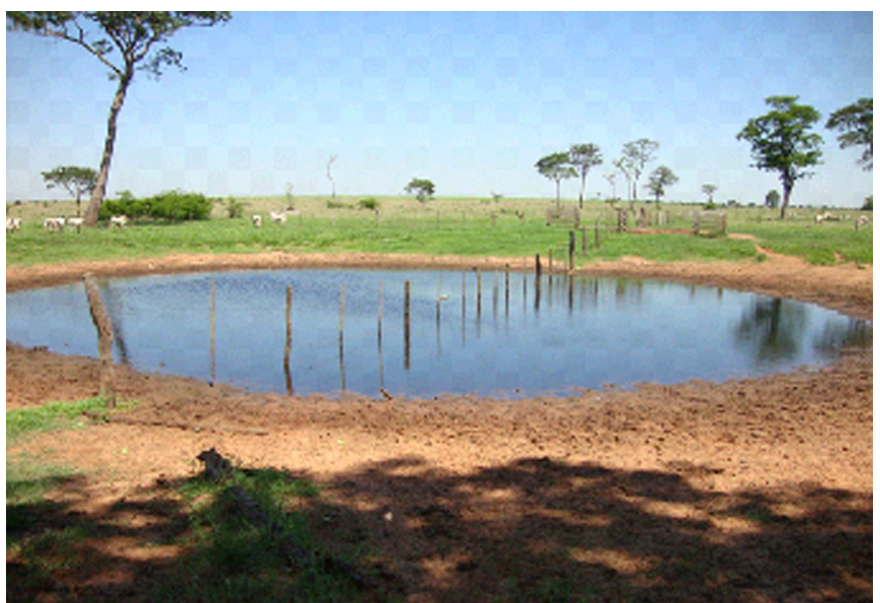

Fig.2. Cacimba empregada na dessedentação de bovinos criados extensivamente, associada a episódios sanitários com alta morbidade e baixa mortalidade de etiologia não comprovada em anos anteriores. Brasilândia, Mato Grosso do Sul.

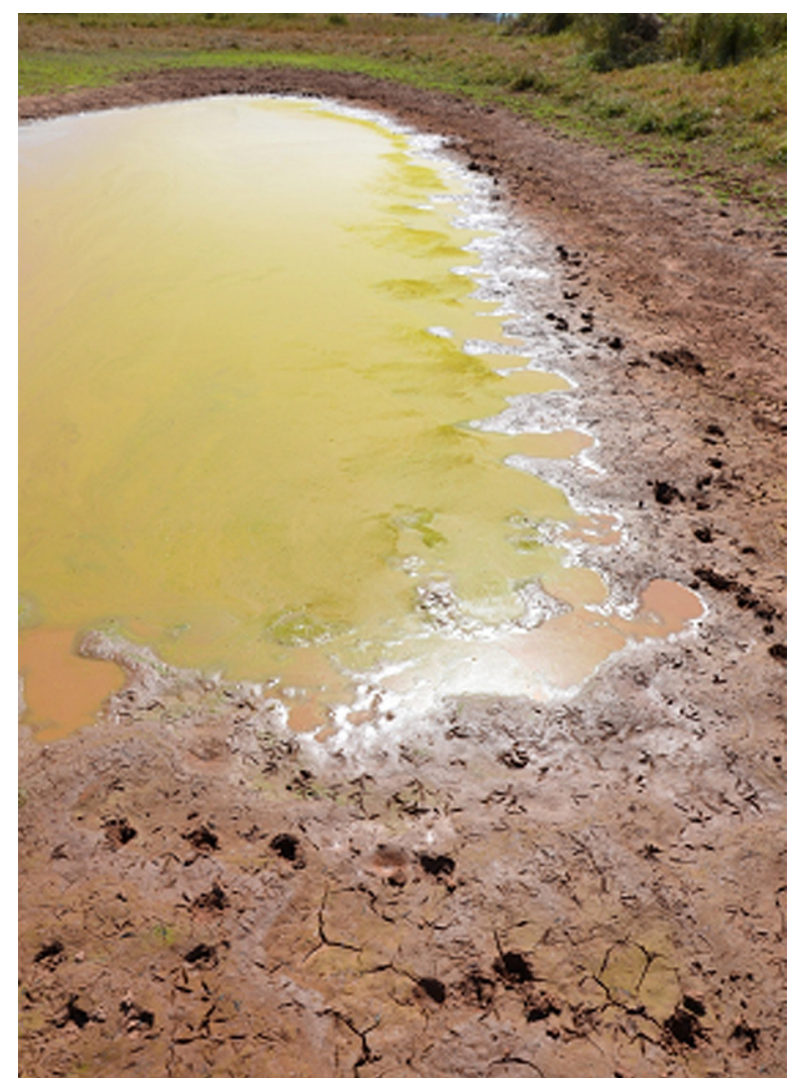

Fig.3. Floração visível de Microcystis em cacimba empregada na dessedentação de bovinos. Município de Lavínia, São Paulo.

nitário de etiologia não diagnosticada. Nas duas ocasiões os bovinos apresentaram severa diarréia e irritação da pele que resultou em alopécia nos jarretes e partes inferiores dos membros; que cessaram com a retirada dos animais dos pastos. Os dois episódios coincidiram com a ocorrência de florações no período seco e redução na quantidade de água do bebedouro formado naturalmente em uma área de depressão. Neste mesmo bebedouro, que não havia presença visível de floração no momento da coleta, foram detectadas ainda algas consideradas não patogênicas dos gêneros Navicula, Pinnularia, Stauroneis, Scenedesmus, Spirogyra, Closterium, Pediastrum e Euglena. Cabe ressaltar que as células de dormência de M. aeruginosa, ao contrário de outras cianobactérias, não são diferenciadas das células vegetativas, sendo capazes de sobreviver por vários anos, à espera de períodos mais favoráveis ao seu desenvolvimento e reprodução (Paerl 1988), o que indica a probabilidade de ocorrência de novas florações neste bebedouro.

A ocorrência de Microcystis em processo de floração típica foi observada em coleção de água de propriedade rural localizada em Lavínia (Fig.3). 0 surgimento da floração ocorreu em um período de aproximadamente uma semana, coincidindo com a retirada dos animais que estavam na pastagem. Dez dias após a coleta de material a cacimba secou. Esta dinâmica relacionada à constante oscilação do volume de água existente nas pequenas coleções de água na pecuária extensiva é cíclica e reflexo de vários fatores que circunstancialmente favorecem a ocorrência de florações, modificando-se em seguida.

Nas outras amostras analisadas não foi possível identificar a presença de cianobactérias, e em apenas um outro bebedouro, de propriedade rural situada em Guararapes (SP), foram identificadas algas dos gêneros Hyalotheca, Spondylorium, Closterium, Microsteria, Pediastrum, Spirogyra e Zygnema.

As situações aqui descritas representam bem a dinâmica do que ocorre com a oferta de água superficial de bebida na pecuária extensiva. Por um lado, é uma situação própria dos sistemas de produção; por outro, representa riscos sanitários potencialmente crescentes na bovinocultura extensiva; à semelhança do que ocorre com o crescimento populacional urbano que acarreta o aumento dos riscos de eutrofização dos ecossistemas aquáticos (Tundisi 2003). Nesse contexto, a ocorrência de algas e cianobactérias planctônicas são indicadores biológicos de grande valor na avaliação da qualidade de água de bebida dos bovinos e deveria também ser considerada quando da adoção de medidas corretivas e preventivas na prática pecuária extensiva.

A ocorrência de Microcystis e Merismopedia nos bebedouros ou cacimbas não significa necessariamente perigo imediato à saúde animal, pois diversos outros elementos devem ser considerados, como a existência de floração e se a espécie é potencialmente produtora de toxinas. Dentre os 15 gêneros e mais de 200 espécies de cianobactérias (Hoek et al. 1995), é considerável o número de espécies tóxicas. No presente estudo a classificação taxonômica foi realizada ao nível de gênero e não foram realizados estudos quantitativos e de toxicidade; no entanto, parte significativa das espécies de ambos os gêneros é potencialmente produtora de toxinas, são competidoras entre si e são comuns em águas rasas e eutrofizadas (Komárek 2003).

A taxonomia do gênero Microcystis é problemática, complexa e com grande variabilidade morfológica. Das 25 espécies de Microcystis conhecidas, muitas delas são formadoras de floração e pelo menos $50 \%$ ocorrem em regiões tropicais e sub-tropicais (Komárek et al. 2002). Segundo Zagatto (1997), mais de 65\% dos casos de intoxicação de humanos e animais seriam causados por espécies desta 
cianobactéria. 0 gênero Merismopedia tem mais de 30 espécies descritas, com as mesmas complexidades (Carmichael 1994).

Os valores de $\mathrm{pH}$, temperatura e oxigênio dissolvido nas 19 coleções oscilaram entre 7,2-9,7, 31-34 ${ }^{\circ} \mathrm{C}$ e 7,8$30 \mathrm{mg} / \mathrm{l}$, respectivamente. Segundo Oliver \& Ganf (2000), a temperatura da água acima de $20^{\circ} \mathrm{C}$, ambientes com pouca luminosidade e baixa razão nitrogênio total/fósforo total, pouca herbívoria pelo zooplâncton, presença de aerótopos que auxiliam o deslocamento na coluna de água, baixa concentração de $\mathrm{CO}_{2}$, dentre outros, são fatores que propiciam grande vantagem competitiva e o desenvolvimento das cianobactérias.

Essas variáveis, embora tenham sido tomadas em uma única avaliação, representam um potencial relativamente favorável para a proliferação de algas e cianobactérias. Além disso, $\mathrm{pH}$ neutroalcalino e temperaturas acima de $20^{\circ} \mathrm{C}$ também beneficiam a ocorrência de florações nos ecossistemas aquáticos (Chorus \& Bartram 1999). Mesmo que algumas cacimbas possam apresentar valores com alta concentração de oxigênio dissolvido, podem também indicar que o ambiente esteja eutrofizado, ou seja, uma água eutrofizada pode apresentar concentrações de oxigênio bem superiores a $10 \mathrm{mg} /$ litro, mesmo em temperaturas superiores a $20^{\circ} \mathrm{C}$, caracterizando uma situação de supersaturação. Isto ocorre principalmente em locais de baixa velocidade da água, na qual chegam a se formar crostas verdes de algas à superfície (Braile \& Cavalcanti 1993).

A capacidade de crescimento nos mais diferentes meios é uma das características marcantes das cianobactérias (Funasa 2003). Diversas espécies podem viver em solos onde desempenham um importante papel nos processos funcionais do ecossistema e ambientes de água doce são os mais importantes para o crescimento de cianobactérias (Azevedo 1998). A flexibilidade das cianobactérias é devido a fatores tanto bioquímicos, fisiológicos, genéticos e reprodutivos (Carmichael 1994), que neste caso se associam às condições ambientais e de manejo criadas nos sistemas de produção extensivos em que os animais têm à disposição para a sua dessedentação coleções de água estagnada em volume e profundidade variáveis ao longo das épocas do ano, que potencialmente passam pelo processo de eutrofização e estão contaminadas.

As cianobactérias do gênero Merismopedia produzem lipopolissacarídeos (dermatotoxina), que são conhecidos por irritarem a pele e também causar distúrbios gastrointestinais (Carmichael 1994). São colônias comumente encontradas nos sedimentos de fontes de água doce. Suas cepas sobrevivem nesse ambiente, criando tróficos e relações simbióticas com outros organismos aquáticos, tais como o zooplâncton. Por outro lado, espécies de Microcystis produzem microcistinas, que são heptapeptídeos cíclicos. Elas são encontradas em todos os continentes e comumente estão presentes em reservatórios de água doce, são extremamente resistentes e bioacumulam-se nos alimentos (Aboal \& Puig 2005).

A microcistina é a hepatotoxina mais estudada dentre as cianotoxinas. Embora não tenha sido objetivo do trabalho detectar a microcistina, a sua presença está associada ao surgimento de floração por espécies de Microcystis, principalmente quando elas formam espuma na superfície da água (Fig.3). A formação de espuma pode ser usada como um indicativo de microcistina, mas a ausência de espuma não quer dizer ausência de cianotoxina, pois até mesmo outras cianobactérias produtoras de microcistinas podem estar presentes, como no caso da Planktothrix agardhii e $P$. rubescens (Fastner et al. 1999).

Paerl \& Huisman (2008) descrevem que o processo de aquecimento global poderá intensificar a formação de florações em razão do aumento da temperatura média da água em ecossistemas aquáticos, o que promoverá, também, a estratificação térmica por períodos mais longos, condições propícias para a dominância de cianobactérias. Nessas circunstâncias, situações como as aqui descritas e amplamente encontradas na pecuária extensiva, em que os animais acessam as cacimbas eutrofizadas, criam condições favoráveis para a proliferação de cianobactérias tóxicas e riscos para a saúde dos animais.

Agradecimentos.- Ao Prof. Dr. Alessandro Minillo, Unesp-Ilha Solteira, pelo auxílio e colaboração nos procedimentos das análises.

\section{REFERÊNCIAS}

Aboal M. \& Puig M.A. 2005. Intracellular and dissolved microcystin in reservoir of the river Segura basin, Murcia, SE, Spain. Toxicon 45:509-518.

American Public Health Association 1998. Standard Methods for the Examination of Water and Wastewater. $20^{\text {th }}$ ed. Washington, DC.1085p.

Assis R.S.S. 2006. Remoção de Microcystis aeruginosa e microcistinas por flotação por ar dissolvido: estudo em escala de bancada utilizando sulfato de alumínio e cloreto férrico como coagulantes. Dissertação de Mestrado, Universidade de Brasília, Brasília, DF.

Azevedo S.M.F.O. 1998. Toxinas de cianobactérias: causas e consequências para a saúde pública. Disponível em <http://www.medonline.com.br/ med_ed/med3/microcis.htm> Acesso em 9 abr. 2011.

Braile P.M. \& Cavalcanti J.E.W. 1993. Manual de Tratamento de Águas Residuárias Industriais. Cetesb, São Paulo.

Carmichael W.W. 1992. Cyanobacteria secondary metabolites: the cyanotoxins. J. Appl. Bacteriol. 72:445-459.

Carmichael W.W. 1994. The toxins of cyanobacteria. Scientific American 270(1):78-86.

Chorus I. \& Bartram J. 1999. Toxic cyanobacteria in water: a guide to their public health consequences, Monitoring and Management. E. and F.N. Spon, New York. 416p.

Domingos P. 2001. Dominância de cianobactérias produtoras de microcistinas na lagoa de Jacarepaguá (RJ). Tese de Doutorado em Biotecnologia Vegetal, Programa de Pós-Graduação em Biotecnologia Vegetal, Universidade Federal do Rio de Janeiro, Rio de Janeiro, RJ. 193p.

Falconer I.R. 1993. Mechanism of toxicity of cyclic peptide toxins from blue-green algae, p.165-176. In: Falconer I.R. (Ed.), Algal Toxins in Seafood and Drinking Water. Academic Press, London.

Falconer I.R. 1998. Algal toxins and human health, p.53-82. In: Hrubec J. (Ed.), Handbook of Environmental Chemistry. Vol.5. Part C. Quality and Treatment of Drinking Water II. Springer-Verlag. Berlin.

Falconer I.R. 1999. An overview of problem caused by toxic blue-green algae (Cyanobacteria) in drinking and recreational water. Environ. Toxicol. 14:5-12.

Falconer I.R., Burch M.D., Steffensen D.A., Choice M. \& Coverdale O.R. 1994. Toxicity of the blue-green alga (Cyanobacterium) Microcystis aeruginosa in drinking water to growing pigs, as an animal model for human injury and risk assessment. J. Environ. Toxicol. Water Qual. 9:131-139.

Fastner J., Erhard M., Carmichael W.W., Sun F., Rinehart K.L., Ronicke H. \& 
Chorus I. 1999. Characterization and diversity of microcystins in natural bloons and strains of the genera Microcystis and Planktothrix from German freshwaters. Arch. Hydrobiol. 145:147-163.

Fonseca F.S. 2007. Microcistina em água superficial no Noroeste Paulista e avaliação de parâmetros que favorecem sua produção. Dissertação de Mestrado, Pós-Graduação em Ciências da Coordenadoria de Controle de Doenças, Secretaria de Estado da Saúde de São Paulo, São Paulo. $119 p$.

Funasa 2003. Cianobactérias Tóxicas na Água para Consumo Humano na Saúde Pública e Processos de Remoção em Água para Consumo Humano: 1. Tratamento da água. 2. Qualidade da água. 3. Vigilância ambiental. Fundação Nacional de Saúde, Ministério da Saúde, Brasília. 56p.

Hoek C., Mann D.G. \& Jahns H.M. 1995. Algae: an introduction to phycology. Cambridge University. 627p.

Jardim F.A., Moreira A.A., Santos D.M., Pimenta M.C.A. \& Giani A. 2007. Avaliação química das florações de Cianobactérias: uma ferramenta útil para o monitoramento. 24을 Congresso Brasileiro de Engenharia Sanitária e Ambiental, Belo Horizonte, MG. ABES - Associação Brasileira de Engenharia Sanitária e Ambiental, p.1-8.

Kellerman T.S., Coetzer J.A.W., Naudé T.W. \& Botha C.J. 2005. Plant Poisonings and Mycotoxicoses of Livestock in Southern Africa. Oxford University Press, Cape Town. 310p.

Komárek J., Komárková-Legnerová J., Sant'Anna C.L., Azevedo M.T.P. \& Senna P.A. 2002. Two common Microcystis species from tropical America. Criptogamie/Algologie 23:159-177.

Komárek J. 2003. Coccoid and Colonial Cyanobacteria, p.59-196. In: Wehr J.D. \& Sheath R.G. (Eds), Freshwater Algae of North America: ecology and classification. Elsevier Science, USA. 918p.

Magalhães A.B.S., Aguiar R.M. \& Magalhães M.A. 2006. Isolamento de cianobactérias potencialmente tóxicas dos pontos de captação de água para o consumo humano do município de Viçosa, Minas Gerais, Brasil.
Congresso Interamericano de Ingeniería Sanitaria y Ambiental, Punta Del Este. Associación Interamericana de Ingeniería Sanitaria y Ambiental, Aidis, p.1-8.

McDermott C.M., Nho C.W., Howard W. \& Holton B. 1998. The cyanobacterial toxin, microcystin-LR, can induceapoptosis in a variety of cell types. Toxicon 36(12):1981-1996.

Oliver R.L. \& Ganf G.G. 2000. Freshwater blooms, p.149-194. In: Whitton B.A. \& Potts M. (Eds), The Ecology of Cyanobacteria: their diversity in time and space. Kluwer Academic Publishers, Netherland. 609p.

Paerl H.W. 1988. Nuisance phytoplankton blooms in coastal, estuarine, and inland waters. Limnol. Oceanogr. 33(4, Part 2):823-847.

Paerl H.W. \& Huisman J. 2008. Blooms like it hot. Science 320:57-58.

Sant'Anna C.L. \& Azevedo M.T.P. 2006. Manual ilustrado para identificação e contagem de cianobactérias planctônicas de águas continentais brasileiras. Interciência, Rio de Janeiro. 58p.

Souza A.M., Marques D.F., Döbereiner J. \& Dutra I.S. 2006. Esporos e toxinas de Clostridium botulinum em cacimbas utilizadas como bebedouro de bovinos no Vale do Araguaia, Goiás. Pesq. Vet. Bras. 26(3):133-138.

Tundisi J.G. 2003. Água no século XXI: enfrentando a escassez. RiMa, Instituto Internacional de Ecologia, São Carlos. 247p.

Veiga N.C.A.R. 2008. Cianobactéria tóxica na água para consumo humano. Disponível em<http://www.viannajredu.br/site/menu/publicacoes/ publicacao_tecnologos/artigos/edicao4/Artigo5.pdf> Acesso em 10 mar. 2011.

Zagatto P.A. 1997. Manual de Orientação em Casos de Florações de Algas Tóxicas: um problema ambiental e de saúde pública. Série Manuais, Cetesb, São Paulo. 20p.

Zhan L., Sakamoto H., Sakuraba M., Wu S., Zhang L.S., Suzuki T., Hayashi M. \& Honma M. 2004. Genotoxicity of microcystin-LR in human lymphoblastoid Tk6 cells. Mutation Research 557(1):01-06. 